\title{
COMPARAÇÃO DA ATIVIDADE ANTIOXIDANTE DE DIFERENTES PARTES DA Solanum paniculatum $\mathrm{L}$.
}

\author{
Bruno Edberg Alves de Lira ${ }^{1 *}$, Rafael Jorge Santos Aracati Padilha ${ }^{1}$, Beatriz Santana Rocha ${ }^{1}$, Maria Cristina Ribeiro \\ da Silva ${ }^{1}$, Ricardo Yara ${ }^{2}$, Cláudia Sampaio de Andrade Lima ${ }^{1}$ \\ ${ }^{1}$ Laboratório de Biofísica Química, UFPE; ${ }^{2}$ Laboratório de Engenharia Biomédica, UFPE \\ *edbergbruno00@gmail.com
}

\section{INTRODUÇÃO}

Os radicais livres e outros oxidantes como as espécies reativas de oxigênio, vem sendo considerados nos últimos anos como grandes causadores de várias doenças como câncer, doenças cardiovasculares, declínio do sistema imune, disfunções cerebrais, bem como outras doenças degenerativas associadas ao envelhecimento (SOUSA et al., 2007). Assim, a absorção de substâ ncias antioxidantes exógenas, por exemplo, através da dieta, acaba se tornando um aliado para a manutenção do balanço oxidativo e da saúde do organismo humano (CERQUEIRA \& AUGUSTO, 2007). Com isso pesquisas tem se voltado para o desenvolvimento de produtos naturais com atividade antioxidante como as plantas medicinais e os fitoterápicos, visto que alguns metabolitos secundários de plantas possuem tal atividade. Metabólitos secundários isolados de plantas como certos compostos fenólicos estão diretamente relacionados a ação antioxidante. Estes compostos podem ser encontrados tanto em plantas não comestíveis como em frutos ou em qualquer outra planta que possa entrar na alimentação, seja humana ou de animal (ARAUJO, 2012). A Solanum paniculatum L. é uma espécie pertencente à família solanaceae, que são fontes ricas de metabolitos secundários, como alcaloides, flavonoides, esteroides, saponinas entre outros (GRIFFIN; LIMA, 2000; VAZ, 2008), conhecida popularmente por jurubeba ou jurubeba-verdadeira e está amplamente distribuída pelo nordeste brasileiro (CORRÊA, 1975). Ela é uma planta muito utilizada na medicina popular brasileira como tônico, antitérmico, no tratamento de disfunções gastro-hepáticas e inibidor da secreçã o do acido gástrico, validando seu uso como medicamento popular (MESIA-VELA et al., 2002).

Já foi relatado na literatura que os extratos de Solanum nigrum $L$. apresentaram uma das maiores capacidades antioxidante pelo mé todo do DPPH (AL- FATIMI et al., 2007), contudo sabe-se que o teor e a composição de compostos são sujeitos a variações climáticas, é pocas de coleta e partes de uma planta (LOURA, 2015). Desta forma o objetivo deste trabalho foi avaliar e comparar a capacidade antioxidante da folha, casca e semente da Solanum paniculatum L. através do método de sequestro do radical livre estável 2,2-difenil-1-picril-hidrazil, coletado no Agreste Pernambucano.

\section{MATERIAIS E MÉTODOS}

As partes de Solanum paniculatum L. foram coletadas na no assentamento de Normandia - Caruaru. 0 material foi acondicionado em estufa com circulação de ar forçada a uma temperatura de $42^{\circ}$. Após secagem foram separadas as folhas, as sementes manualmente dos frutos e cascas e em seguida cada parte foi triturada e posteriormente acondicionada em recipientes protegidos da luz onde foi adicionado etanol para obtenção do extrato bruto, foram realizadas cinco filtrações com intervalos de 48 horas. 0 extrato bruto obtido foi levado a evaporador rotativo $\left(45^{\circ} \mathrm{C}\right)$ para retirada total do solvente.

Para avalição da atividade antioxidante foi utilizado o método do sequestro do radical livre estável 2,2-defini-1-picril-hidrazil (DPPH), que possui a cor purpura, quando em contato com um antioxidante ou uma espécie radicalar o DPPH é reduzido apresentando uma coloração amarela, podendo a atividade antioxidante ser determinada devido à diminuição da absorbância (NASCIMENTO et al., 2011).

A partir dos extratos etanólicos foram preparadas as soluções das amostras em triplicata nas concentrações de 1000, 500, 250, 125, $62,5 \mu \mathrm{g} / \mathrm{mL}$. O controle negativo foi feito pela adição de etanol e DPPH. Adicionou-se $2 \mathrm{~mL}$ de solução etanólica de DPPH a 12\% em cada concentração. Após 30 minutos foi feita a leitura da absorbâ ncia no espectrofotômetro a $515 \mathrm{~nm}$. O percentual da atividade antioxidante $(\mathrm{AA} \%)$ foi calculado utilizando-se a media de absorbâ ncia e a seguinte equação:

Eliminação [DPPH] $(\%)=\frac{(\text { Abs amostra }- \text { Abs controle })}{\text { Abs controle }} \times 100$

Onde: Abs (Absorbância)

Para a obtenção da curva de calibração preparou-se uma solução etanólica de DPPH na concentração de $300 \mu \mathrm{Mol}(120 \mu \mathrm{g} / \mathrm{mL})$. Em seguida, foram preparadas diluições dessa solução para obtenção de diferentes concentrações 100, 80, 60, 40, 20, 10, 5 e $1 \mu \mathrm{g} / \mathrm{mL}$. Foram feitas as leituras das absorbâncias das soluções, em triplicata, utilizando-se etanol como branco. Foi construída a curva padrão de DPPH plotando-se o valor médio das absorbâncias obtidas x concentração da solução (NASCIMENTO et al., 2011).

\section{RESULTADOS E DISCUSSÃO}

Os resultados da avaliação da atividade antioxidante dos extratos etanólicos de $S$. paniculatum (folha, casca e semente), nas concentrações de 1000, 500, 250, 125 e $62,5 \mu \mathrm{g} / \mathrm{mL}$, determinadas pelo ensaio do DPPH, conforme Tabela 1.

Tabela 1. Resultados teste antioxidante pela redução do radical DPPH para os extratos de $S$. paniculatum. 


\begin{tabular}{cccc}
\hline $\begin{array}{c}\text { Concentrações } \\
\boldsymbol{\mu g} / \mathrm{mL}\end{array}$ & $\begin{array}{c}\text { Jurubeba } \\
\text { folha(AA\%) }\end{array}$ & $\begin{array}{c}\text { Jurubeba } \\
\text { semente(AA\%) }\end{array}$ & $\begin{array}{c}\text { Jurubeba } \\
\text { casca(AA\%) }\end{array}$ \\
\hline 1000 & 96,24 & 81,71 & 96,75 \\
500 & 94,07 & 67,63 & 76,29 \\
250 & 72,69 & 57,95 & 64,34 \\
125 & 60,61 & 54,2 & 55,48 \\
62,5 & 54,46 & 53,49 & 52,17 \\
\hline
\end{tabular}

Os resultados indicam que a atividade antioxidante para a concentração de $1000 \mu \mathrm{g} / \mathrm{mL}$ foram superiores a $90 \%$ tanto para a folha como casca e acima de $80 \%$ para a semente, segundo protocolo estabelecido. Diante do exposto pode-se propor que a ação antioxidante está distribuída em várias partes da planta e podem estar relacionadas a várias ações biológicas já destacadas na literatura como tônica, desobstruente e digestiva. De acordo com AL- FATIMI e cols. (2007) o gênero Solanum possui várias espé cies descritas na literatura que se destacam por possuírem atividade antioxidante como S. incanum e S. nigrum, devido ao teor de flavonoides e ácidos clorogênicos presente (AL- FATIMI et al., 2007).

\section{CONCLUSÕES}

Nas condições desse estudo foi possível observar que os extratos etanólicos da Solanum paniculatum L. mostraram potencial agente oxidante in vitro (pela técnica do DPPH) apresentando resultados satisfatórios para todas as partes analisadas e em todas as concentrações. No entanto é necessária a realização de mais estudos para a caracterização fitoquimica desta espécie e melhor compreensão da relação entre seus metabolitos e as atividades biológicas exercidas.

Apoio:

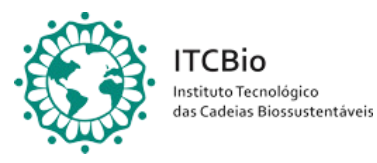

\section{REFERÊNCIAS}

AL-FATIMI, M.; WURSTER, M.; SCHRÖDER, G.; \& Lindequist, U. Antioxidant, antimicrobial and cytotoxic activities of selected medicinal plants from Yemen. J. Ethnopharmacol. v. 111, p. 657666, 2007.

ARAUJO, T. A. de S. Atividade antioxidante de plantas medicinais da Caatinga e Mata Atlântica: aspectos etnobotânicos e ecológicos. Tese, Universidade Federal de Pernambuco, 2012.

CERQUEIRA, F. M.; MEDEIROS, M. H.G. de; AUGUSTO, O.

Antioxidantes dietéticos: controvérsias e perspectivas. Quim.

Nova, v. 30, n. 2, p. 441-449, 20

GRIFFIN, J.W.; LINA, G.D. Chemotaxonomy and geographcal distribution of tropane alcaloides. Phitochemistry, v. 53, n. 6, p. 623-637, 2000.

LOURA, L. G. Variação Sazonal, HOrário de coleta e potencial antimicrobiano do óleo Cinnamodendron dinisii Scwacke. Dissertaç ão - Universidade Federal de Lavras, 2015

MESIA-VELA, S.; SANTOS, M.T.; SOUCCAR, C.; LIMA-LANDMAN M.T.R.; LAPA, A.J. Solanum paniculatum L. (jurubeba): potent inhibitor of gastric acid secretion in mice. Phytomedicine, v. 9 n.6 p. 508 - 514, 2002.

NASCIMENTO J.C.; LAGE L.F.O.; CAMARGOS C.R.D.; AMARAL J.C.; COSTA L.M.; SOUSA N.A.; OLIVEIRA F.Q. Determinação da atividade antioxidante pelo método DPPH e doseamento de flavonóides totais em extratos de folhas da Bauhinia variegata L. Rev. Bras. Farm., v. 92 n. 4, P. 327-332, 2011.
SOUSA, C.M.M.; SILVA, H.R.; VIEIRA, G.M.; AYRES, M.C.C.; COSTA, C.S.; ARAÚJO, D.S. Fenóis totais e atividade antioxidante de cinco plantas medicinais. Química Nova, v. 30, n. 2, p. 351-355, 2007. 07.

VAZ, N.P. Alcalóides Esteroidais dos Frutos Maduros de Solanum caavurana vell.101f. dissertação (mestrado de química) - Setor de Ciências Exatas, Universidade Federal do Paraná. Curitiba, 2008. CORRÊA, M.P. Dicionário de Plantas Úteis do Brasil e das Exóticas Cultivadas. Vol.2, Rio de Janeiro: Imprensa Nacional, completado por Leonandia Azeredo, (1926-1975). $271 \mathrm{p}$.

VELIOGLU, Y. S.; Mazza, G.; GAO, L.; \& OOMAH, B. D . Antioxidant activity and total phenolics in selected fruits, vegetables, and grain products. J. Agric. Food Chem. v. 46, n. 10, p. 4113 4117, 1998. 